\title{
Splicing defect in FKBP10 gene causes autosomal recessive osteogenesis imperfecta disease: a case report
}

\author{
Fatemeh Maghami ${ }^{1}$, Seyed Mohammad Bagher Tabei ${ }^{1}$, Hossein Moravej ${ }^{2}$, Hassan Dastsooz ${ }^{3}$, Farzaneh Modarresi ${ }^{4}$, \\ Mohammad Silawi ${ }^{3}$ and Mohammad Ali Faghihi $i^{3,4^{*}}$
}

\begin{abstract}
Background: Osteogenesis imperfecta $(\mathrm{OI})$ is a group of connective tissue disorder caused by mutations of genes involved in the production of collagen and its supporting proteins. Although the majority of reported Ol variants are in COLIA1 and COL1A2 genes, recent reports have shown problems in other non-collagenous genes involved in the post translational modifications, folding and transport, transcription and proliferation of osteoblasts, bone mineralization, and cell signaling. Up to now, 17 types of OI have been reported in which types I to IV are the most frequent cases with autosomal dominant pattern of inheritance.

Case Presentation: Here we report an 8- year- old boy with Ol who has had multiple fractures since birth and now he is wheelchair-dependent. To identify genetic cause of Ol in our patient, whole exome sequencing (WES) was carried out and it revealed a novel deleterious homozygote splice acceptor site mutation (c.1257-2A > G, IVS7$2 \mathrm{~A}>\mathrm{G})$ in FKBP10 gene in the patient. Then, the identified mutation was confirmed using Sanger sequencing in the proband as homozygous and in his parents as heterozygous, indicating its autosomal recessive pattern of inheritance. In addition, we performed RT-PCR on RNA transcripts originated from skin fibroblast of the proband to analyze the functional effect of the mutation on splicing pattern of FKBP10 gene and it showed skipping of the exon 8 of this gene. Moreover, Real-Time PCR was carried out to quantify the expression level of FKBP10 in the proband and his family members in which it revealed nearly the full decrease in the level of FKBP10 expression in the proband and around $75 \%$ decrease in its level in the carriers of the mutation, strongly suggesting the pathogenicity of the mutation.
\end{abstract}

Conclusions: Our study identified, for the first time, a private pathogenic splice site mutation in FKBP10 gene and further prove the involvement of this gene in the rare cases of autosomal recessive OI type XI with distinguished clinical manifestations.

Keywords: Osteogenesis imperfect (OI), FKBP10, Novel splice mutation, Case report

\section{Background}

Osteogenesis imperfecta (OI) (also known as brittle bone disease) is a heterogeneous group of connective tissue disorders characterized by easy and frequent fractures in long bones leading to malformation, disability and wheelchair dependence [1]. Other less frequent symptoms are short

\footnotetext{
* Correspondence: MFaghihi@med.miami.edu

${ }^{3}$ Persian BayanGene Research and Training Center, Dr. Faghihi's Medical Genetics Center, Shiraz, Iran

${ }^{4}$ Center for Therapeutic Innovation, Department of Psychiatry and Behavioral Sciences, University of Miami Miller School of Medicine, 1501 NW 10th Ave, BRB 508, Miami, FL 33136, USA

Full list of author information is available at the end of the article
}

stature, bluish sclera, dentinogenesis imperfecta and hearing impairment [2]. Clinical presentations of the disease range from mild asymptomatic forms with an increased tendency to fracture to more severe neonatal forms with early death due to multiple bone and spine fractures [3].

The David Sillence's classification of OI included types I to IV [4]; but, now this classification has been extended to XVII groups. The inheritance pattern of types I to $\mathrm{V}$ is autosomal dominant but types VI to XVII which are the rare forms of the disease are presented with autosomal recessive inheritance [5-7].

(c) The Author(s). 2018 Open Access This article is distributed under the terms of the Creative Commons Attribution 4.0 International License (http://creativecommons.org/licenses/by/4.0/), which permits unrestricted use, distribution, and reproduction in any medium, provided you give appropriate credit to the original author(s) and the source, provide a link to the Creative Commons license, and indicate if changes were made. The Creative Commons Public Domain Dedication waiver (http://creativecommons.org/publicdomain/zero/1.0/) applies to the data made available in this article, unless otherwise stated. 
The mutations responsible for OI types I, II, III, and IV which are the most common form of OI (85-90\%) occur in either the COL1A1 or COL1A2 gene, encoding type I collagen [3, 8-10]. But, mutations in other genes are accounted for other types of the disease, presenting $10-15 \%$ of all cases with autosomal recessive inheritance [11] (Additional file 1: Table S1). OI incidence has been reported as high as $1 / 15,000$ to $1 / 20,000$ live births [12] but in Iranian population the frequency has not been estimated yet.

The aim of current study was to identify diseasecausing mutation in an affected boy with OI without prior history of OI in his parents and extended family members.

\section{Case Presentation}

The proband is an 8-year-old Iranian boy who was born to consanguineous marriage partners (first-degree cousins) by full-term normal vaginal delivery (NVD). He had birth weight of $3400 \mathrm{~g}$, birth length of $50 \mathrm{~cm}$ and head circumference of $35 \mathrm{~cm}$. It is worth noting that the first fracture was observed in elbow during delivery and other fractures were seen at the age of 2 and 5 months in other long bones, followed by several fractures in all bones. After receiving intravenous Pamidronate, every 3 months, number of fractures reduced from 7 to 8 per year to only 2 per year. The intellectual capacity was intact and cognitive function was in normal range. Clinical findings were also observed as blue sclera, which was diminished with age. Hearing loss, dental eruption, and symptoms of contracture deformity (reduced ability to move an area of his body) have not been observed in the patient. Echocardiography was performed which showed normal heart function. Also, abdominal ultrasonography revealed normal size of liver and spleen. He is currently wheelchair dependent and able to take few steps using walker stand. Now, he has height of $102 \mathrm{~cm}(-4.3 \mathrm{SD})$, head circumference of 47.5 (10th centile) and weight of $14,600 \mathrm{~g}$ (25th centile). Repeated radiologic reports were in favor of OI with reduced bone density and multiple fractures in various stages of healing. Laboratory tests were also performed for the proband which revealed following results: increased levels of calcium $(10.7 \mathrm{mg} / \mathrm{dl}$, normal range: $8.8-10.2 \mathrm{mg} / \mathrm{dl})$ and sodium $(139 \mathrm{mEq} / \mathrm{L}$, normal range: 6-20 mEq/L), but normal levels of phosphorus $(5.8 \mathrm{mg} / \mathrm{dl}$, normal range: $4-6.5 \mathrm{mg} / \mathrm{dl}$ ), potassium (4.1 $\mathrm{mEq} / \mathrm{L}$, normal range: $3.5-5 \mathrm{mEq} / \mathrm{L})$, and alkaline phosphatase (650 unit/liter, normal range: $180-$ $1200 \mathrm{U} / \mathrm{L})$. Also, thyroid and kidney function tests were reported in normal range.

The mother of proband was also pregnant and prenatal diagnosis test on chorionic villus sample (CVS) showed that fetus had the same pathogenic mutation like the proband. Therefore, the pregnancy was terminated therapeutically at the 18 weeks of gestation.

\section{Whole Exome Sequencing (WES)}

To investigate disease causing mutation in our patient, WES was performed to amplify and sequence all exons of protein-coding genes as well as some other important genomic regions. In our study, next generation sequencing was carried out to sequence close to 42 million reads on Ion Proton Sequencer. In general, test platform examined $>95 \%$ of the targeted regions with sensitivity of above $99 \%$. In this test, point mutations and microinsertion/deletions and duplication $(<20 \mathrm{bp})$ can be simultaneously identified. Bioinformatics analysis of the sequencing results was performed using BWA aligner [13], GATK [14] and Annovar open access software [15] as well as public databases and standard bioinformatics software. Sequences text files were aligned using BWA aligner tool, variants were identified using GATK and then annotated utilizing annovar software.

\section{Sanger Sequencing}

To confirm the presence and the pattern of inheritance of a novel identified mutation, peripheral blood samples were obtained from proband, his parents, grandparents from both sides, and other extended family members. All samples were processed for DNA extraction using QIAamp DNA Blood Mini Kit (Cat No./ID: 51104, Germany) according to the manufacturer's instructions. Moreover, DNA of CVS sample was extracted using QIAamp DNA Mini Kit (Cat No./ID: 51304, Germany). Following primers were used to amplify exon eight of FKBP10 gene as well as its flanking intronic sequences to look for the mutation: FKBP10_E8_F: ccaagtcaccagtgggagta and FKBP10_E8_R: ttatggtctcagccctcac. Amplified DNA was sequenced from both directions using Sanger Sequencing kit (ABI BigDye Terminator Cycle Sequencing Kit, Applied Biosystems ${ }^{\oplus}$, USA) according to the company protocol. Then, Sanger sequencing data was analyzed using NCBI BLAST and 4Peaks free software.

\section{RT-PCR}

In current study, commercially available cDNA from various human tissues were analyzed to identify the tissues with expression of FKBP10 gene. Also, RNA was extracted from peripheral blood and skin biopsy samples (the skin fibroblast culture conditions is given in Additional file 1) of the proband and his parents using TriPure (Additional file 1) and RNeasy Mini Kit (QIAGEN, Germany), respectively. RNA concentration, purity, and integrity were assessed using NanoDrop ND1000 spectrophotometer (Thermo Fisher Scientific) and electrophoresis of the $2 \mu \mathrm{L}$ extracted RNA on $2 \%$ 
agarose gel containing SYBR Safe ${ }^{\mathrm{Tx}}$ DNA gel stain (Invitrogen) under the ultraviolet (UV) light. The isolated RNA was stored at $-20{ }^{\circ} \mathrm{C}$ until use. Then, they were subjected to cDNA synthesis using SuperScript FirstStrand Synthesis System for RT-PCR (Invitrogen, USA) according to the standard company protocol. The resulted cDNA samples were used for performing RT-PCR using primers spanning exon 7, 8 and 9 of FKBP10 transcript (Sense-Primer: 5'gaactggagacaagatccet 3' and Antisence-Primer: 5' cttgatgaaggtggagaactc 3', Product: $526 \mathrm{bp}$ ) and then the results were compared to normal cDNA sequence for identification of any changes in the transcript splicing events.

\section{Quantitative Real Time PCR}

Real-Time PCR using PowerUp SYBR Green Master Mix (ABI, USA, Cat number: A25918) on Applied Biosystems 7500 Real-time PCR System was performed in triplicate to investigate any reduction in FKBP10 gene expression in the skin biopsies from the proband and his parents compared to normal controls (Additional file 1). In this study, human Glyceraldehyde 3-phosphate dehydrogenase (GAPDH) was used as reference gene. Following Exon-Exon Junction primer pairs were used in our Real-Time PCR for the interested gene (F-QPCR- FKBP10: gttcacctcgcatgactac and R-QPCR- FKBP10: cctctctccacacacat) and GAPDH gene (F-QPCR-GAPDH: gctctctgctcctcctgttc and R-QPCR-GAP DH: cgaccaaatccgttgactcc).

\section{Results}

NGS result revealed that the proband was homozygous for a splice-acceptor mutation in FKBP10 gene (FKBP10201: ENST00000321562.8, NM_021939.3: c.1257-2A > G, IVS7-2A > G). This novel homozygous variant is located in position $39,977,197$ on chromosome 17q21.2 close to exon 8 in FKBP10 gene. It is predicted that this splice site change can lead to a frameshift mutation in FKBP10 protein (FKBP10-201: ENST00000321562.8, NM_021939.3: p.H420PfsX12). All information about this mutation and all bioinformatics software which were used to predict the functional effects of this mutation are given in Additional file 1: Table S2. This mutation is predicted to be pathogenic using MutationTaster tool and highly conserved using Phastcons and GERP program (Additional file 1: Table S2). Allele frequency for this mutation is not available in ExAC (http://exac.broadinstitute.org/), GnomAD (http://gnomad.broadinstitute.org/), Kaviar (http://db.systemsbiology.net/kaviar/cgi-pub/Kaviar.pl), GME (http:// igm.ucsd.edu/gme/), ESP (http://evs.gs.washington.edu/ EVS/), 1000Genomes (http://www.internationalgenome. org/1000-genomes-browsers) and our database (1000 Iranian whole exome sequencing data as BayanGene). There is no report in literatures on pathologic manifestation of this mutation and its phenotype relation to the OI type XI or Bruck syndrome, so this mutation is considered as novel variant.

Sanger sequencing results revealed that proband and fetus were homozygous for this new mutation but both his mother and father as well as three of his grandparents were heterozygous for the mutation (Fig. 1), indicating the autosomal recessive pattern of inheritance for this disease. Also, it confirmed that the observed genotype in the proband, his parents, and extended family members segregates with the disease phenotype.

Moreover, RT-PCR analysis of commercially available cDNA from lung, brain, muscle, kidney, heart, and liver and also skin biopsy samples from patient showed the presence of FKBP10 transcript (Fig. 2a, b). As can be seen in Fig. 3a, RT-PCR showed exon 8 skipping since it produced a sharp PCR band of $300 \mathrm{bp}$ (skipped product) and a week PCR band of $526 \mathrm{bp}$ (normal product) in the proband compared to 526 bp with sharp PCR band and $300 \mathrm{bp}$ with weak PCR band in a normal heterozygous sample. In addition, Sanger sequencing from the $300 \mathrm{bp}$ product provided from the proband confirmed the exon 8 skipping (Fig. 3b).

Real-Time PCR on skin biopsies from the proband and his father clearly showed nearly the full depletion in the level of FKBP1O expression in the proband and around $25 \%$ expression of $F K B P 10$ in his parents compared to normal controls, confirming exon 8 skipping and frameshift truncation of FKBP10 protein (Fig. 4 a-c). As can be observed in the Fig. 4b, a leaky expression of FKBP1O is seen in the proband with both mutated copies of FKBP10 gene. Therefore, segregation studies using Sanger sequencing, RT-PCR, and Real-Time PCR analysis confirmed the pathogenicity of this splice site mutation in FKBP10 gene.

\section{Discussion and Conclusions}

OI is a heterogeneous disease resulted from diseasecausing mutations in different genes contributing to 17 different types of OI $[2,16]$. Type XI OI is resulted from disease causing mutations in FKBP10 gene. This gene is located on long arm of chromosome 17 (17q21.2) consisted of 10 exons which is encoded for a highly conserved family of intracellular proteins called immunophilins [17, 18]. This protein is essential for proper formation and balance between elastin and collagen molecules presented in the extracellular matrix [19]. Also, this protein acts as molecular chaperon and have important roles in collagen biosynthesis and folding [19, 20]. Cross linking between collagen molecules creates durable collagen molecules which resist fractures. It should be noted that an important role of FKBP10 protein can be considered in the hydroxylation of collagen prior to cross link formation [20]. Therefore, any 


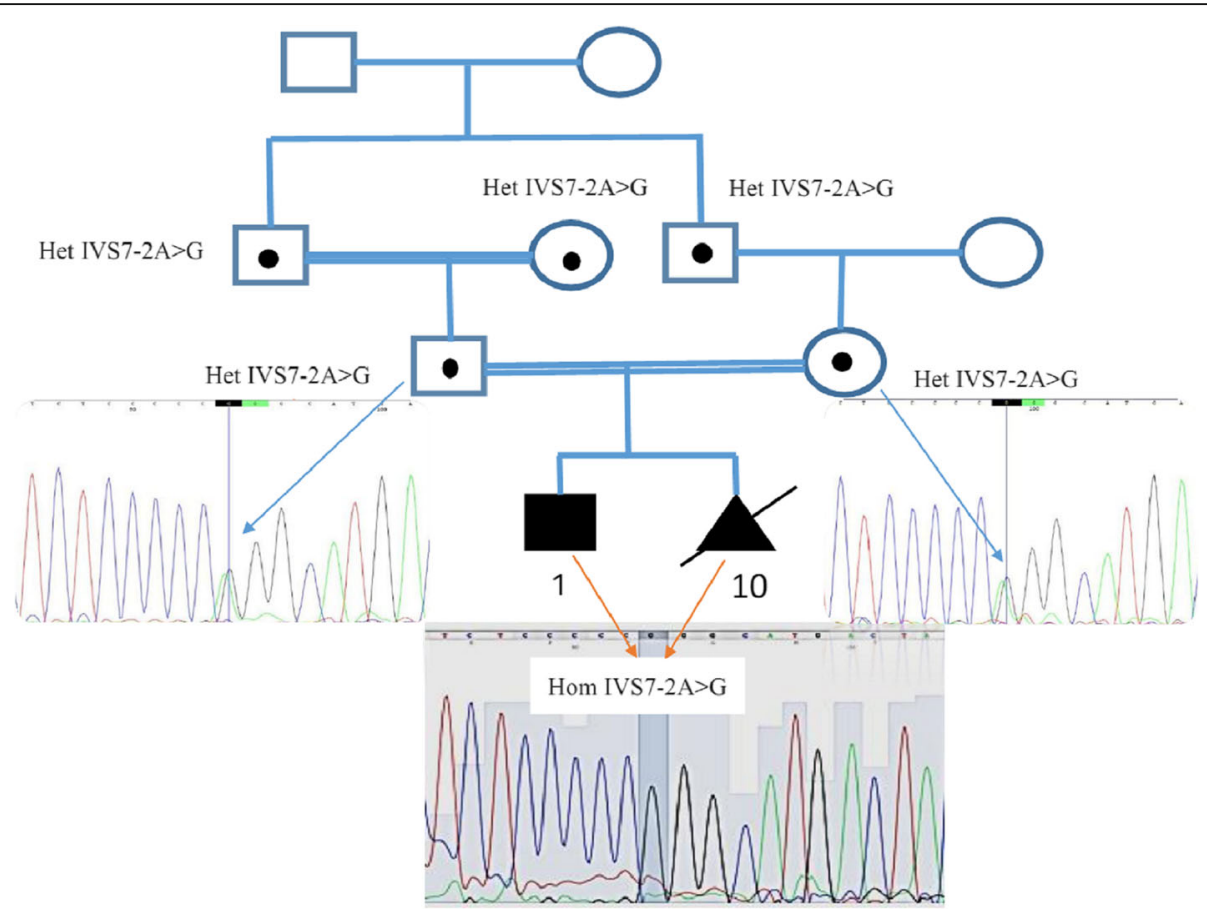

Fig. 1 Pedigree and Sanger sequencing details. Using Sanger sequencing, the inheritance mode of autosomal recessive was confirmed in this family based on identified homozygote mutation in the proband and heterozygote mutation in his parents and three of his grandparents. Here only sequencing graph from the proband and his parents are given. Het: Heterozygous. Hom: Homozygous

impaired FKBP10 protein can be deleterious in the establishment of durable collagen molecules.

For the first time, Alanay et al. in 2010 reported that a mutation of FKBP10 gene is involved in OI type XI [3]. They studied a cohort of five consanguineous Turkish families, and also a Mexican-American family with moderately severe recessively inherited OI. They identified a $4 \mathrm{Mb}$ region, a locus for OI, on chromosome 17 spanning FKBP10 gene and then it was reported as a candidate gene for OI type XI. They sequenced all ten exons of FKBP10 gene using Sanger sequencing technique to detect the causative gene in their study.
Since the first report, several mutations have been identified in FKBP1O gene. It is worth to note that homozygous mutations in FKBP10 have been previously reported in OI type XI (OMIM number 610968), an autosomal recessive form of OI. In addition, mutations in FKBP10 have been found in Bruck Syndrome 1 (OMIM number 259450), a musculoskeletal disorder with some overlapping phenotypes with OI. In our study we identified a private splicing mutation in this gene using next generation sequencing which caused its exon 8 skipping, resulting to a frameshift mutation and truncation of FKBP10 protein. As described in the result
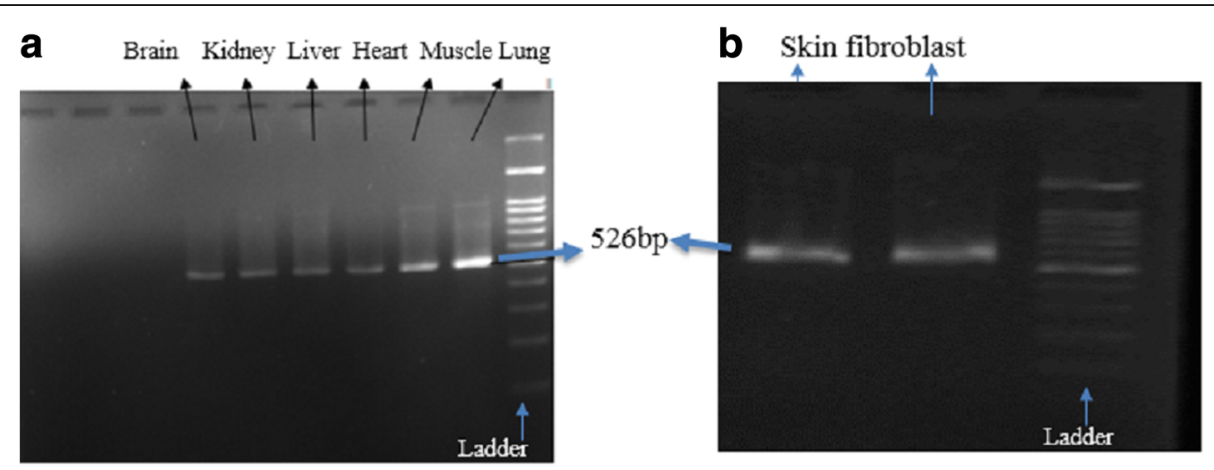

Fig. 2 a). RT-PCR for identification of FKBP10 gene expression in several commercially available CDNAs from various human tissues. It can be seen that the expression of this gene is observed in brain, liver, kidney, heart, muscle, and lung. b). RT-PCR shows the presence of FKBP10 transcript in skin biopsy samples in the normal indivitual 


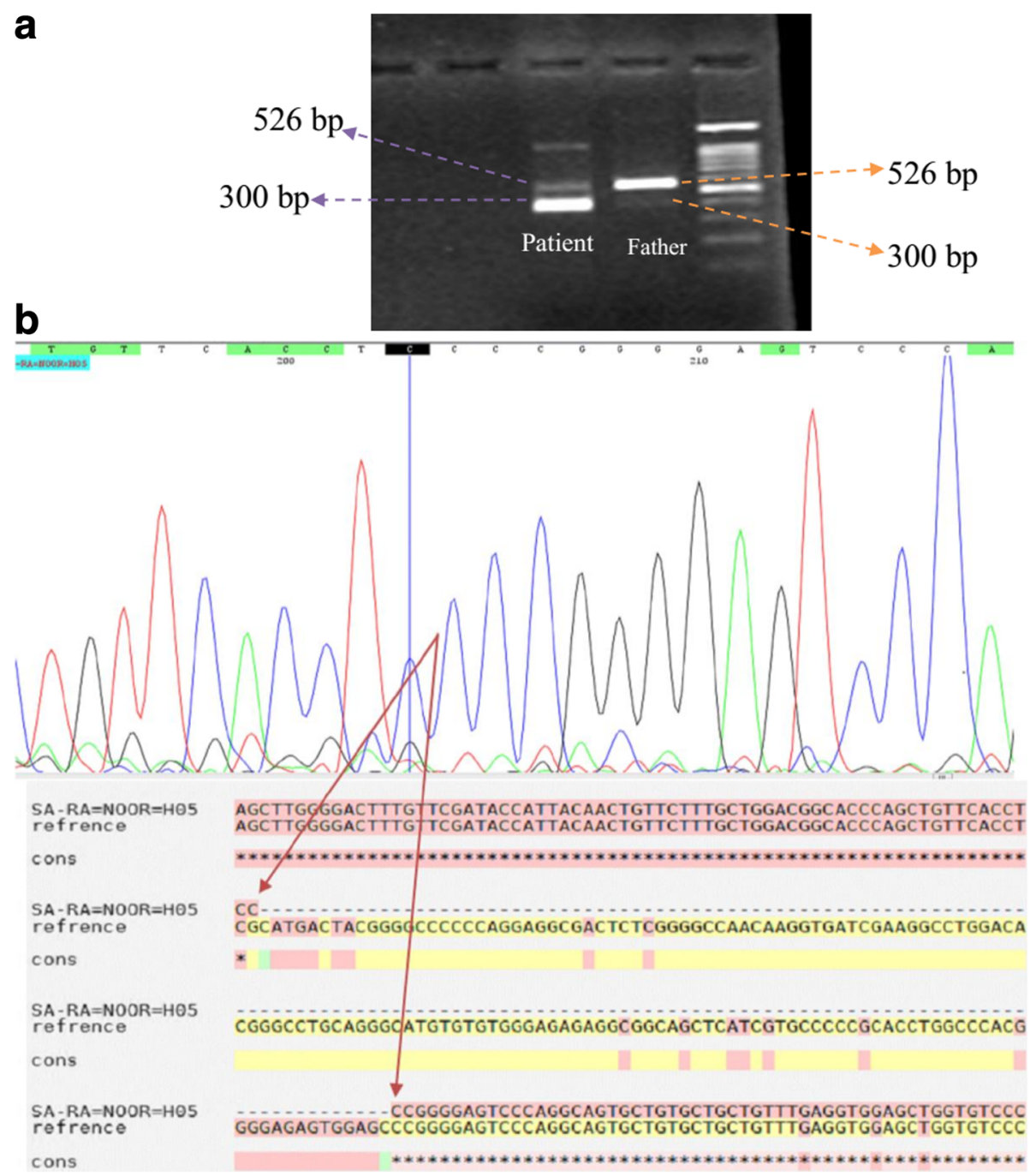

Fig. 3 a). RT-PCR shows exon 8 skipping which produces a sharp skipped product of 300 bp and a week normal PCR band of 526 bp in the proband but in his father, a $526 \mathrm{bp}$ with sharp PCR band and $300 \mathrm{bp}$ with weak PCR band is detected. b). Sequencing data of skipped product (300 bp) from proband. Data was blasted to reference FKBP10 transcript and confirmed the exon 8 skipping. $\left(^{*}\right)$ symbol: Cons: conserved nucleotide in the blast. $(-)$ symbol: deleted nucleotide

section, this mutation can cause leaky expression of FKBP10 gene but the few produced transcripts are not sufficient to prevent the clinical abnormalities in the patient. In addition, in the heterozygous individual we expected to observe around 50\% decrease in the expression levels of this gene but nearly $25 \%$ expression of this gene was detected without any clinical findings in the heterozygous case. Current study uncovered that this mutation is pathogenic in our patient affected by OI type XI. Therefore, our study is in accordance with study conducted by Alanay et al. in 2010 [3] and can be considered as OI type XI with moderate to severe and progressive nature of phenotype.

As mentioned above, the splicing mutation found in our study causes the production of mRNA molecule with lack of exon 8 producing truncated FKBP10 protein without the last PPIase and HEEL domains. In addition, defects in FKBP10 lead to accumulation of type I procollagen due to a delayed secretion [3]. However, further studies are needed to find which mechanisms are involved in the nearly full lack of FKBP10 transcripts and why the leaky expression of this gene is not sufficient to reduce the clinical presentations. Moreover, the functional analysis of FKBP10 gene in the mutant cells and its effect on gene expression of type I collagen should be elucidated.

In conclusion, in current study a novel splice-acceptor mutation in FKBP1O gene was identified which segregated with the disease phenotype (an autosomal recessive form of OI). The mutation is a private mutation 


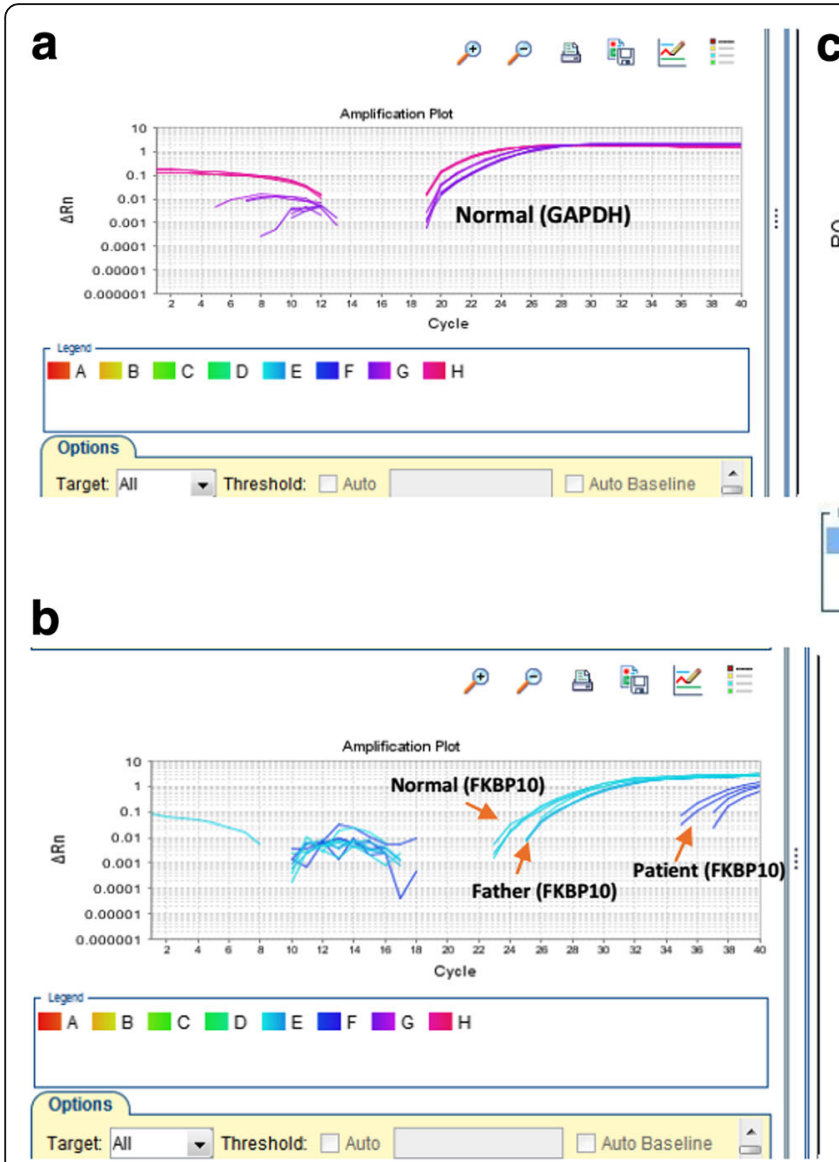

Fig. 4 Real-Time analysis of GAPDH and FKBP10 gene in the patient, his father and normal individual. a). As seen in this figure, GAPDH expression shows same levels for the patient, his father and normal individual b). Comparison between expression levels of FKBP10 shows different levels in the proband, heterozygous individual and normal individual c). Relative quantification (RQ) result. It shows that normal individual (the calibrator) has a RQ value of 1 meaning no changes in its expression level but in the proband RQ is zero which indicates no expression of FKBP10. In his father, the gene is 75 times less expressed

without previous reports or documents in the checked variation databases such as ExAC, GenomAD, Kaviar, GME, ESP, and 1000Genomes. In addition, the effects of this mutation on exclusion of exon 8 was confirmed using Sanger sequencing, RT-PCR and Real-Time PCR on RNA samples derived from skin biopsy of the proband and carrier members. This study can prove the strong link between FKBP10 gene and collagen fiber arrangement in bone tissue.

\section{Additional file}

Additional file 1: Material and Methods, two supplementary tables, Description of data: Detail description of Fibroblast culture, Isolation of PBMCs and Quantitative RT-PCR. Table S1. List of all genes involved in Osteogenesis imperfecta. Table S2. Bioinformatics analysis statistics. (DOCX $25 \mathrm{~kb}$ )

\section{Abbreviations}

MAF: Minor allele frequency; NGS: Next generation sequencing;

NMD: Nonsense-mediated decay mechanisms; NVD: Normal vaginal delivery;

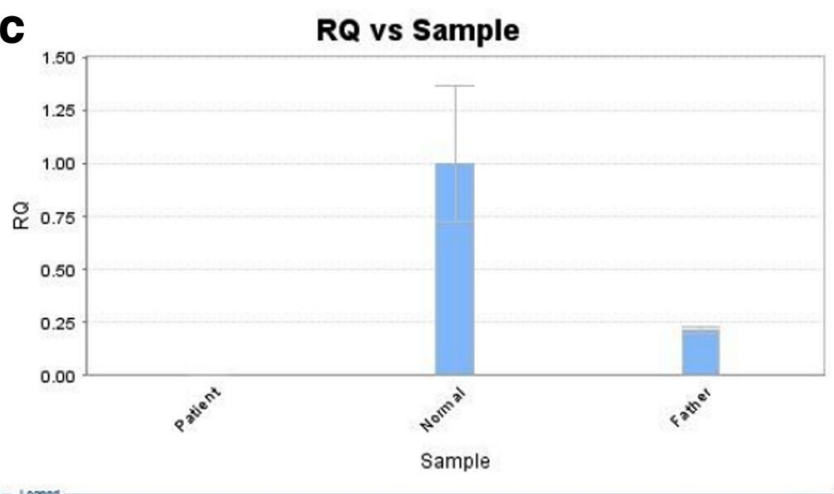

FKBP10 
bioinformatics data. MS performed the experiments and edited the manuscript. All authors have read and approved the manuscript for publication.

\section{Ethics approval and consent to participate}

Ethic committee at Shiraz University of Medical Sciences has approved the study. The parents of affected individual have signed written consent for the publication and participation on behalf of the minor. The extended family members have signed written consent indicating their voluntary contribution to the current study. One of the parent donated skin biopsy for splicing studies and extended family members gave blood samples for segregation studies.

\section{Consent for publication}

The parents of affected individual have signed written consent for the publication of identifying images or other personal or clinical details on behalf of the minor.

\section{Competing interests}

The authors declare that they have no competing interests.

\section{Publisher's Note}

Springer Nature remains neutral with regard to jurisdictional claims in published maps and institutional affiliations.

\section{Author details}

'Department of Medical Genetics, Medical School, Shiraz University of Medical Sciences, Shiraz, Iran. ${ }^{2}$ Pediatric Department, School of Medicine, Shiraz University of Medical Sciences, Shiraz, Iran. ${ }^{3}$ Persian BayanGene Research and Training Center, Dr. Faghihi's Medical Genetics Center, Shiraz, Iran. ${ }^{4}$ Center for Therapeutic Innovation, Department of Psychiatry and Behavioral Sciences, University of Miami Miller School of Medicine, 1501 NW 10th Ave, BRB 508, Miami, FL 33136, USA.

\section{Received: 4 October 2017 Accepted: 18 April 2018}

Published online: 25 May 2018

\section{References}

1. Van Dijk F, Sillence D. Osteogenesis imperfecta: clinical diagnosis, nomenclature and severity assessment. Am J Med Genet A. 2014;164(6): 1470-81.

2. Rauch F, Glorieux FH. Osteogenesis imperfecta. Lancet. 2004;363(9418): 1377-85.

3. Alanay $\mathrm{Y}$, Avaygan $\mathrm{H}$, Camacho N, Utine GE, Boduroglu K, Aktas D, Alikasifoglu M, Tuncbilek E, Orhan D, Bakar FT. Mutations in the gene encoding the RER protein FKBP65 cause autosomal-recessive osteogenesis imperfecta. Am J Hum Genet. 2010;86(4):551-9.

4. Sillence DO, Senn A, Danks DM. Genetic heterogeneity in osteogenesis imperfecta. J Med Genet. 1979;16(2):101-16.

5. Marini JC, Cabral WA, Barnes AM, Chang W. Components of the collagen prolyl 3-hydroxylation complex are crucial for normal bone development. Cell Cycle. 2007;6(14):1675-81.

6. Barnes AM, Carter EM, Cabral WA, Weis M, Chang W, Makareeva E, Leikin S, Rotimi CN, Eyre DR, Raggio CL, et al. Lack of cyclophilin B in osteogenesis imperfecta with normal collagen folding. N Engl J Med. 2010;362(6):521-8.

7. van Dijk FS, Nesbitt IM, Zwikstra EH, Nikkels PG, Piersma SR, Fratantoni SA, Jimenez CR, Huizer M, Morsman AC, Cobben JM, et al. PPIB mutations cause severe osteogenesis imperfecta. Am J Hum Genet. 2009;85(4):521-7.

8. Cabral WA, Chang W, Barnes AM, Weis M, Scott MA, Leikin S, Makareeva E, Kuznetsova NV, Rosenbaum KN, Tifft CJ. Corrigendum: Prolyl 3-hydroxylase 1 deficiency causes a recessive metabolic bone disorder resembling lethal/ severe osteogenesis imperfecta. Nat Genet. 2008;40(7):927.

9. Christiansen HE, Schwarze U, Pyott SM, AlSwaid A, Al Balwi M, Alrasheed S, Pepin MG, Weis MA, Eyre DR, Byers PH. Homozygosity for a missense mutation in SERPINH1, which encodes the collagen chaperone protein HSP47, results in severe recessive osteogenesis imperfecta. Am J Hum Genet. 2010;86(3):389-98.

10. Alanay Y, Bank RA, Campos-Xavier AB, Zankl A, Superti-Furga A, Bonafé L. Phenotypic and molecular characterization of Bruck syndrome (osteogenesis imperfecta with contractures of the large joints) caused by a recessive mutation in PLOD2. Am J Med Genet A. 2004;131(2):115-20.
11. Barnes AM, Cabral WA, Weis M, Makareeva E, Mertz EL, Leikin S, Eyre D, Trujillo C, Marini JC. Absence of FKBP10 in recessive type XI osteogenesis imperfecta leads to diminished collagen cross-linking and reduced collagen deposition in extracellular matrix. Hum Mutat. 2012;33(11):1589-98.

12. Forlino A, Marini JC. Osteogenesis imperfecta. Lancet (London, England). 2016;387(10028):1657-71.

13. Li H, Durbin R. Fast and accurate short read alignment with BurrowsWheeler transform. Bioinformatics. 2009;25(14):1754-60.

14. McKenna A, Hanna M, Banks E, Sivachenko A, Cibulskis K, Kernytsky A, Garimella K, Altshuler D, Gabriel S, Daly M, et al. The Genome Analysis Toolkit: a MapReduce framework for analyzing next-generation DNA sequencing data. Genome Res. 2010;20(9):1297-303.

15. Wang K, Li M, Hakonarson H. ANNOVAR: functional annotation of genetic variants from high-throughput sequencing data. Nucleic Acids Res. 2010; 38(16):e164.

16. Forlino A, Cabral WA, Barnes AM, Marini JC. New perspectives on osteogenesis imperfecta. Nat Rev Endocrinol. 2011;7(9):540-57.

17. Schreiber SL. Chemistry and biology of the immunophilins and their immunosuppressive ligands. Science. 1991;251(4991):283-7.

18. Galat A. Peptidylproline cis-trans-isomerases: immunophilins. Eur J Biochem. 1993;216(3):689-707.

19. Patterson CE, Abrams WR, Wolter NE, Rosenbloom J, Davis EC. Developmental regulation and coordinate reexpression of FKBP65 with extracellular matrix proteins after lung injury suggest a specialized function for this endoplasmic reticulum immunophilin. Cell Stress Chaperones. 2005; 10(4):285-95.

20. Ishikawa Y, Vranka J, Wirz J, Nagata K, Bächinger HP. The rough endoplasmic reticulum-resident FK506-binding protein FKBP65 is a molecular chaperone that interacts with collagens. J Biol Chem. 2008;283(46):31584-90.

\section{Ready to submit your research? Choose BMC and benefit from:}

- fast, convenient online submission

- thorough peer review by experienced researchers in your field

- rapid publication on acceptance

- support for research data, including large and complex data types

- gold Open Access which fosters wider collaboration and increased citations

- maximum visibility for your research: over $100 \mathrm{M}$ website views per year

At BMC, research is always in progress.

Learn more biomedcentral.com/submissions 